\title{
Influence of sensory integration training on mental mobility of elderly people with $\mathrm{MCl}$
}

\author{
Zhang Hongmei \\ Qingdao Binhai College, Qingdao, Shandong, 266555
}

\begin{abstract}
With increasing age, in general, the human intelligence level is gradually decreasing. Mild cognitive impairment, abbreviated as MCI, is a type of cognitive dysfunction that commonly occurs in the aged and balances the normal state of aging and senile dementia. Mild cognitive impairment is easily converted to Alzheimer's disease elderly if it is not controlled in time. In order to study how to better train the aged in MCI and design related training systems to help the aged to delay the MCI's circle, a sensory comprehensive training is conducted to study on the impact of mental mobility in the old MCI in this article. The final research results show that sensory integration training can improve the state of mental mobility in MCI elderly by strengthening the training of MCI elderly sense andtouch.
\end{abstract}

\section{INTRODUCTION}

Mild cognitive impairment, abbreviated as MCI, occurs frequently disease with elderly people over 60 years old. And who are mainly engaged in manual labor before retirement, have low education level, have bad habits such as smoking and drinking are high-risk groups. Mild cognitive impairment is an intermediate state between normal aging and dementia, so this population is also a high-risk group that may develop dementia.

According a report from Professor Jia Jianping, elderly persons with mild cognitive impairment are nearly four times more than the total number of dementias, and the large number of high-level people is rare in the world (Myer G D, et al, 2011) [1]. According to domestic and foreign data, China is the first country with large population of Alzheimer's disease, and the quality of life of patients is severely affected by the Alzheimer's disease. The average survival rate of that disease is $8-10$ years, which brings great care burden to the family members (Boswell J F, et al, 2010) [2]. Professor Wang Jun, vice chairman of the International Alzheimer's Association China Committee, said that mild cognitive impairment is the best treatment and prevention stage for Alzheimer's disease. Through the investigation of hospitals and related data, it is learned that the current domestic hospitals are relatively backward in terms of treatment methods. There is no special treatment drug for these patients. And more patients or in the case of family supervision are required to conduct reasonable diet, rest and necessary planned thinking training. However, patients and their families lack understanding of the disease itself, and in the absence of scientific and reasonable training methods and necessary equipment, it is difficult to complete the prescribed training tasks, resulting in deterioration and disgust of the disease and even developing as Alzheimer's disease (Hernández P, et al, 2010) [3].

\section{STATEOFTHEART}

Sensory integration theory was first proposed by American clinical psychologist Aryes AJ according to neurophysiological theory in 1969, referring to the various sensory stimuli information that enters the brain to form an effective combination in the central nervous system and to coordinate corresponding organs and tissues to make the process of appropriate responses. Dr. Ayres emphasized in his theory of sensory integration: "The development of the body's motor, sensory, and cognitive abilities goes hand in hand with the process of brain function maturation." This suggests that sensory integration function is a type of brain function and is the primary link in the ability of the brain to control movement and recognition (Bell B S, et al, 2010) [4].

When sensory stimuli information cannot be effectively combined in the central nervous system, the entire body can't operate in harmony and effectively, called sensory integration disorders (abnormally dysregulated). Sensory integration training uses the plasticity of the nervous system during the ontogeny to stimulate brain function and promote the development of brain nerve cells through training in auditory, visual, the basic sensory, balance, and spatial perception. So this is a training method that the subject can be able to effectively integrate various feelings and to make correct response (Lowndes L, et al, 2010) [5]. As human behavior, the basic sensory systems of motor development (such as tactile system, vestibular sensory system and proprioception) play an important role in the development of human cognition. The development 
process is sensory-perceptual-cognitive function. The implementation of sensory integration training in the form of games for MCI elderly people can better attract their attention and help to effectively enhance physical fitness, promote health, regulate mental status, and enhance adaptive capacity.

\section{METHODOLOGY}

Sensory integration training uses the plasticity of the nervous system during the ontogeny to stimulate brain function and promote the development of brain nerve cells through training in auditory, visual, the basic sensory, balance, and spatial perception. So this is a training method that the subject can be able to effectively integrate various feelings and to make correct response (Petersen R C, et al, 2011) [6].

The most important one in sensory comprehensive training is the training of cognitive ability. The cognitive ability mainly includes the ability of language development and spatiotemporal orientation. MCI old people because of their brain function lesions and poor listening and speaking ability, their language ability degenerate and they are unable to express their wishes. While sensory integration training has a good effect on the language development of MCI elderly people. Sensory integration training is conducted in the form of games. It often requires the cooperation and mutual coordination among the participants to work together, which promotes more communication and exchanges among the elderly in MCI. This kind of communication is beneficial to strengthen the ability of language expression in the MCI elderly (Petersen R C, et al, 2009) [7]. The brain's lower cortical center of the nervous system is responsible for sensory intake, integration, and

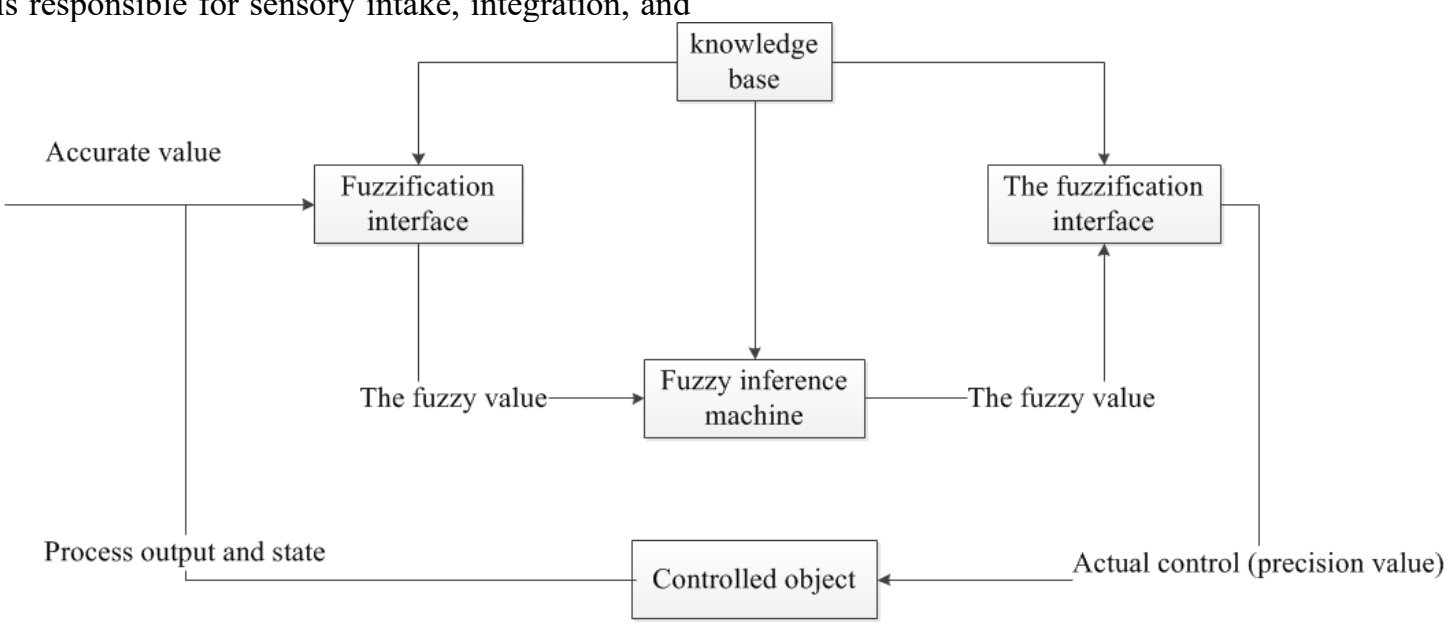

Fig. 1 Fuzzy System Structure

The fuzzy inference engine converts into a certain mapping according to a specific fuzzy rule (Torpy $\mathrm{J} \mathrm{M}$, et al, 2009) [10]. Fuzzy rule is $R_{K}: I F x_{1}$ is $A_{1 M}, x_{2}$ is $A_{2 M}, \ldots, x_{n}$ is $A_{n M}, T H E N y$ is $B_{M}$. This fuzzy rule can be expressed as a point ambiguity function communication, while the higher cortical center is responsible for generalization, perception, reasoning, language, and learning. The latter depends on the former and enables individuals to acquire complex learning skills. One of the functions of sensory integration is to classify the reception of all sensory inputs (such as sight, hearing, touch, pain, balance, sense of body, etc.) that enter the brain, and to interpret, relate and unity spatial and temporal signals from different sensory pathways. Space-time orientation includes out-going, public transportation, time concepts and comprehensive orientation capabilities, which can achieve to strengthen the cognitive ability of time and space by observing and perceiving motion images, experiencing various movement forms, movement sequences, spatial perceptions, time perceptions, and interactions among various parts of the body (Albert M S, et al, 2011) [8].

When testing the cognitive ability of the MCI elderly, the cognitive function assessment software developed by the Shanghai Institute of Mental Health was used to digitally score the cognitive abilities of MCI elderly people. The software tests basic information such as test scores, time and correctness of MCI elderly people with five projects of the digital connection, graphic recognition, picture response, spatial memory, and visual tracking.

In addition, in this experiment, the acquired data needs to be fuzzy processed by the fuzzy system so that the data can be better analyzed. The fuzzy system includes a knowledge base, a fuzzy interface, a fuzzy inference engine, and an anti-fuzzification interface, based on the fuzzy set, and is a dynamic model that targets fuzzy information (Frank A R, et al, 2008) [9]. The fuzzy system structure is shown in Figure 1. 
and different control rules are reflected. In order to achieve the control of the control object, a precise control quantity needs to be judged and the center of gravity method is used to realize the process of defuzzification. The formula is shown in Formula 1:

$$
U_{j}^{i k}=\sum_{i=1}^{M} \mu\left(U_{i j}\right) U_{i j} / \sum_{i=1}^{M} \mu\left(U_{i j}\right)
$$

Among them, $U_{j}^{i k}$ is the output of the controller, $U_{i j}$ and $\mu\left(U_{i j}\right)$ are the fuzzy set value and membership function of the fuzzy output variable.

\section{RESULTAND ALYSISDISCUSSION}

In order to study the effect of sensory comprehensive training on the mental mobility of MCI elderly, $14 \mathrm{MCI}$ old people were selected for cognitive psychology experiments with the consent of the patient's family members and doctors where are 8 men and 6 women.

In this study, the subjects were divided into two groups: the test group and the contrast group, and the sample size were 7 in each group. In order to avoid the sample difference, before the experiment, the correlation $\mathrm{T}$ test of the two groups of test data showed that $\mathrm{P}>0.05$, which indicates that there was no significant difference between the test group and the contrast group in each test item. Then 14 MCI old people were numbered and balloted to determine experimental groupings and implement training interventions.

The first experimental project is digital connection test, as shown in Table 1, which is a comparative analysis of the digital connection test results between the test group and the contrast group.

Table.1 Comparison and Analysis of Digital Connection Test Results between Test Group and Contrast Group

\begin{tabular}{|c|c|c|c|c|}
\hline Test items & $\begin{array}{c}\text { Training } \\
\text { phase } \\
\text { (before } \\
\text { or after) }\end{array}$ & $\begin{array}{c}\text { test } \\
\text { group } \\
(\mathrm{N}=7)\end{array}$ & $\begin{array}{l}\text { contrast } \\
\text { group } \\
(\mathrm{N}=7)\end{array}$ & $\mathrm{P}$ \\
\hline \multirow{3}{*}{$\begin{array}{c}\text { Completion } \\
\text { time } \\
\mathrm{P}\end{array}$} & before & $\begin{array}{r}38.57 \pm \\
19.99\end{array}$ & $37.85 \pm$ & 0.89 \\
\hline & after & $\begin{array}{c}21.85 \pm \\
10.22\end{array}$ & $\begin{array}{c}35.28 \pm \\
16.15\end{array}$ & 0.03 \\
\hline & & 0.01 & 0.65 & \\
\hline \multirow{3}{*}{$\begin{array}{c}\text { Error count } \\
\text { P }\end{array}$} & before & $\begin{array}{r}0.28 \\
\pm .48 \\
\end{array}$ & $\begin{array}{c}0.42 \pm \\
0.53\end{array}$ & 0.60 \\
\hline & after & 0 & $\begin{array}{c}0.28 \pm \\
487\end{array}$ & 0.01 \\
\hline & & 0.17 & 0.35 & \\
\hline \multirow{3}{*}{$\begin{array}{c}\text { Test score } \\
\text { P }\end{array}$} & before & $\begin{array}{c}30.85 \pm \\
21.50\end{array}$ & $\begin{array}{c}29.71 \pm \\
22.28\end{array}$ & 0.89 \\
\hline & after & $\begin{array}{r}58.85 \pm \\
31.64\end{array}$ & $\begin{array}{c}38.14 \pm \\
22.45\end{array}$ & 0.000 \\
\hline & & 0.000 & 0.27 & \\
\hline
\end{tabular}

Table 1 shows that there is no significant difference between the test group and the contrast group in the digital connection test results before the training, and $\mathrm{P}>$ 0.05. After training, the comparison of groups shows that the MCI older people's digital connection test ability of the test group is higher than that of the control group, and $\mathrm{P}<0.05$. The comparison between the experimental data of the "Completion Time" project shows that the average time used in the test group after training is significantly lower than that of the control group. It can be seen that the digital connection time of MCI elderly in the test group accelerated, which indicates that the attention distraction ability of the elderly in MCI is significantly improved, while in the contrast group, the completion time is improved but it is not significant because there were fewer usual training opportunities. The project data of "Error count" indicates the times that the old MCI did not connect the numbers correctly. The greater the error rate, the worse the memory capacity of MCI old people for the 10-digit Arabic numbers. From the table, it can be seen that the data difference between the two groups after training is obvious, in which the MCI elderly of the test group can correctly remember 10-digit numbers and no click error, indicating that training improves the digital memory capacity of MCI elderly and $\mathrm{P}=0.01<0.05$. However, through intra-group comparisons, it is found that there was no significant difference in "Error count" between the test group and the contrast group before and after training and $\mathrm{P}>0.05$, which may relate to the previous learning and memory ability training of the MCI elderly, resulting in a smaller increase in training results. With the "Test Score" project integrated the first two achievements, it is learned that the test scores of the MCI elderly in the test group increased significantly after training. At the same time, the average scores of the two groups of MCI elderly did not reach the score line of 60 points, which shows the ability of the digital connection of the experimental subjects is not high, and need to be lengthened the training period properly to achieve the observation improvement effect. The results of the digital connection test overall indicate that audio-visual sensory integration training can significantly improve the ability of the elderly in MCI of the test group to allocate attention, and improve the ability of digital memory. And it requires a longer period of intensive training to achieve a full standard level.

The second experimental project is image discrimination test, as shown in Table 2, which is a comparative analysis of the image discrimination test results between the test group and the contrast group.

Table.2 Comparison and Analysis of Image Discrimination Test Results between Test Group and Contrast Group

\begin{tabular}{|c|c|c|c|c|}
\hline $\begin{array}{c}\text { Test } \\
\text { items }\end{array}$ & $\begin{array}{c}\text { Training } \\
\text { phase } \\
\text { (before } \\
\text { or after) }\end{array}$ & $\begin{array}{c}\text { test } \\
\text { group } \\
(\mathrm{N}=7)\end{array}$ & $\begin{array}{c}\text { contrast } \\
\text { group } \\
(\mathrm{N}=7)\end{array}$ & $\mathrm{P}$ \\
\hline $\begin{array}{c}\text { Correct } \\
\text { questions } \\
\mathrm{P}\end{array}$ & before & $\begin{array}{c}7.85 \pm \\
1.46\end{array}$ & $\begin{array}{c}7.28 \pm \\
1.70\end{array}$ & 0.42 \\
\cline { 2 - 5 } & after & $\begin{array}{c}9.42 \pm \\
0.78\end{array}$ & $\begin{array}{c}8.00 \pm \\
1.15\end{array}$ & 0.04 \\
\hline
\end{tabular}




\begin{tabular}{|c|c|c|c|c|}
\hline & & 0.03 & 0.32 & \\
\hline \multirow{3}{*}{$\begin{array}{c}\text { Missing } \\
\text { questions } \\
\mathrm{P}\end{array}$} & \multirow{2}{*}{ before } & $\begin{array}{c}1.42 \pm \\
0.53\end{array}$ & $\begin{array}{c}1.42 \pm \\
0.53\end{array}$ & \multirow{2}{*}{1} \\
\cline { 2 - 5 } & \multirow{2}{*}{ after } & $\begin{array}{c}0.53 \pm \\
0.42\end{array}$ & $\begin{array}{r}1.14 \pm \\
0.37\end{array}$ & 0.02 \\
\cline { 2 - 5 } & & 0.01 & 0.28 & \\
\hline $\begin{array}{c}\text { Average } \\
\text { reaction } \\
\text { time } \\
\text { (seconds) }\end{array}$ & before & $\begin{array}{c}0.90 \pm \\
0.22\end{array}$ & $\begin{array}{c}0.92 \pm \\
0.19\end{array}$ & 0.83 \\
\cline { 2 - 5 } $\mathrm{P}$ & after & $\begin{array}{c}0.68 \pm \\
0.18\end{array}$ & $\begin{array}{c}0.82 \pm \\
0.24\end{array}$ & 0.16 \\
\cline { 2 - 5 } & & 0.03 & 0.31 & \\
\hline
\end{tabular}

Table 2 shows that there is no significant difference in the image recognition test score between the test group and the contrast group before training, and $\mathrm{P}>0.05$. After training, there is a significant difference between the "Correct questions" and "Missing questions" between the test group and the contrast group, and $\mathrm{P}<0.05$. The "Average reaction time" score of the experimental subjects had no significant difference after training. Among them, "Correct questions" and "Missing questions" all reflect the visual discrimination ability of the experimental subjects. After training, the old MCI in the test group are able to reach $90 \%$ accuracy rate, 0 missing rate, and the progress of children in the contrast group is not obvious, indicating that sensory integration training can improve the visual abilities of the experimental subjects. The results of the last "Average reaction time" show that there is no difference between the average response time of the two groups of MCI elderly before and after training, and $\mathrm{P}>0.05$. From that, it can be seen that although the operation accuracy rate of the test group of MCI elderly has improved but still takes a long time to response this is consistent with the general cognitive characteristics of MCI elderly. Although there is no significant difference between the groups in the "Average reaction time" item, the improvement effect of the test group before and after training is significant and $\mathrm{P}<0.05$. That indicates the sensory integration training has a significant improvement in the average response time of the MCI elderly in the test group.

The third experiment: image response test, as shown in Table 3, is a comparative analysis of the test results of the reaction between the test group and the contrast group.

Table.3 Comparison and Analysis of Image Reaction Test Results between Test Group and Contrast Group

\begin{tabular}{|c|c|c|c|c|}
\hline $\begin{array}{c}\text { Test } \\
\text { items }\end{array}$ & $\begin{array}{c}\text { Training } \\
\text { phase } \\
\text { (before } \\
\text { or after) }\end{array}$ & $\begin{array}{c}\text { test } \\
\text { group } \\
(\mathrm{N}=7)\end{array}$ & $\begin{array}{c}\text { contrast } \\
\text { group } \\
(\mathrm{N}=7)\end{array}$ & $\mathrm{P}$ \\
\hline \multirow{3}{*}{$\begin{array}{c}\text { Correct } \\
\text { questions } \\
\mathrm{P}\end{array}$} & before & $\begin{array}{c}2.85 \pm \\
0.89\end{array}$ & $\begin{array}{c}2.71 \pm \\
0.75\end{array}$ & 0.73 \\
\cline { 2 - 5 } & after & $\begin{array}{c}3.71 \pm \\
0.48\end{array}$ & $\begin{array}{c}2.57 \pm \\
0.53\end{array}$ & 0.02 \\
\cline { 2 - 5 } & & 0.04 & 0.72 & \\
\hline \multirow{2}{*}{$\begin{array}{c}\text { Error } \\
\text { count } \\
\mathrm{P}\end{array}$} & before & $\begin{array}{c}1.14 \pm \\
0.89\end{array}$ & $\begin{array}{c}1.28 \pm \\
0.75\end{array}$ & 0.72 \\
\cline { 2 - 5 } & after & $0.48 \pm$ & $1.42 \pm$ & 0.02 \\
\hline
\end{tabular}

\begin{tabular}{|c|c|c|c|c|}
\hline & & 0.28 & 0.53 & \\
\cline { 2 - 5 } & & 0.05 & 0.72 & \\
\hline \multirow{4}{*}{$\begin{array}{c}\text { More } \\
\text { questions } \\
\mathrm{P}\end{array}$} & before & $\begin{array}{r}1.28 \pm \\
0.95\end{array}$ & $\begin{array}{r}1.21 \pm \\
1.14\end{array}$ & \multirow{2}{*}{0.73} \\
\cline { 2 - 5 } & after & $\begin{array}{r}0.48 \pm \\
0.28\end{array}$ & $\begin{array}{r}1.28 \pm \\
0.75\end{array}$ & 0.03 \\
\cline { 2 - 5 } & & 0.02 & 0.73 & \\
\hline \multirow{4}{*}{$\begin{array}{c}\text { Test } \\
\text { score } \\
\mathrm{P}\end{array}$} & before & $\begin{array}{r}58.42 \pm \\
21.86\end{array}$ & $\begin{array}{c}54.71 \pm \\
18.49\end{array}$ & \multirow{2}{*}{0.69} \\
\cline { 2 - 5 } & after & $\begin{array}{r}85.80 \pm \\
14.03\end{array}$ & $\begin{array}{c}57.14 \pm \\
18.03\end{array}$ & \multirow{2}{*}{0.01} \\
\cline { 2 - 5 } & & 0.01 & 0.79 & \\
\hline
\end{tabular}

Table 3 shows that there is no significant difference in image test performance between the test group and the contrast group before training, and the $\mathrm{P}$ value is greater than 0.05. After training, the old MCI in the test group is significantly higher than that of the children in the contrast group, the correct rate is $93 \%$, and $\mathrm{P}<0.05$. 与 At the same time, in the 4 image response tests, the "Correct questions" of the test group MCI aged after training is increased to 3-4 questions, basically reaching to each time response timely and to click on the pictures, while the contrast group of MCI elderly had no substantial improvement. "Missing questions" and "More questions " represent the visual reaction control ability of MCI elderly. The increase in the number of " Missing questions" indicates that the visual response of the MCI elderly tested is dull. The increase in the number of " More questions" indicates that the visual response of the MCI elderly tested is overactive and unable to control the operation. Therefore, the data in the table shows that the number of missing questions and more questions in the test group of the MCI elderly after training is basically 0 . And there is no significant change in the contrast group before and after the MCI elderly test. This result shows that sensory integration training has improved the visual response control ability of the MCI elderly. Finally, the "Test score" item comprehensively considers the visual response and control ability of the elderly MCI. The higher the correct rate, the better the comprehensive ability of visual response of the MCI elderly is. Therefore, after the training, the average score of the test group is better than that of the contrast group, which explains that through visual and auditory sensory integration training, the visual response accuracy and control ability of MCI elderly can be improved.

The fourth experiment: the spatial memory test, as shown in Table 4, is a comparative analysis of the spatial memory test results between the test group and the contrast group.

Table.4 Comparison and Analysis of Spatial Memory Test Results between Test Group and Contrast Group

\begin{tabular}{|c|c|c|c|c|}
\hline $\begin{array}{c}\text { Test } \\
\text { items }\end{array}$ & $\begin{array}{c}\text { Training } \\
\text { phase } \\
\text { (before } \\
\text { or after) }\end{array}$ & $\begin{array}{c}\text { test } \\
\text { group } \\
(\mathrm{N}=7)\end{array}$ & $\begin{array}{c}\text { contrast } \\
\text { group } \\
(\mathrm{N}=7)\end{array}$ & $\mathrm{P}$ \\
\hline $\begin{array}{c}\text { Correct } \\
\text { questions }\end{array}$ & before & $\begin{array}{c}2.28 \pm \\
0.95\end{array}$ & $\begin{array}{c}2.14 \pm \\
0.89\end{array}$ & 0.63 \\
\hline
\end{tabular}




\begin{tabular}{|c|c|c|c|c|}
\hline \multirow[t]{2}{*}{$\mathrm{P}$} & after & $\begin{array}{c}2.71 \pm \\
0.48\end{array}$ & $\begin{array}{c}2.00 \pm \\
1.00\end{array}$ & 0.03 \\
\hline & & 0.16 & 0.64 & \\
\hline \multirow{3}{*}{$\begin{array}{l}\text { Wrong } \\
\text { direction } \\
\text { (left and } \\
\text { right) } \\
\text { P }\end{array}$} & before & $\begin{array}{c}0.48 \pm \\
0.28 \\
\end{array}$ & $\begin{array}{c}0.42 \pm \\
0.53 \\
\end{array}$ & 0.68 \\
\hline & after & $\begin{array}{c}0.49 \pm \\
0.28\end{array}$ & $\begin{array}{c}0.42 \pm \\
0.53\end{array}$ & 0.57 \\
\hline & & 0.88 & 0.89 & \\
\hline \multirow{3}{*}{$\begin{array}{l}\text { Wrong } \\
\text { direction } \\
\text { (up and } \\
\text { down) } \\
\text { P }\end{array}$} & before & $\begin{array}{c}0.37 \pm \\
0.14\end{array}$ & $\begin{array}{c}0.36 \pm \\
0.15\end{array}$ & 0.90 \\
\hline & after & 0 & $\begin{array}{c}0.37 \pm \\
0.14\end{array}$ & 0.36 \\
\hline & & 0.45 & 0.90 & \\
\hline \multirow{3}{*}{$\begin{array}{c}\text { Complete } \\
\text { time } \\
\text { P }\end{array}$} & before & $\begin{array}{c}8.71 \pm \\
2.13 \\
\end{array}$ & $\begin{array}{c}8.28 \pm \\
3.35 \\
\end{array}$ & 0.71 \\
\hline & after & $\begin{array}{c}5.57 \pm \\
2.82 \\
\end{array}$ & $\begin{array}{c}7.85 \pm \\
2.54\end{array}$ & 0.17 \\
\hline & & 0.15 & 0.38 & \\
\hline
\end{tabular}

Table 4 mainly examines the short-term memory ability of the experimental subjects for the position of the three images. The data in the table shows that there is no significant difference in the spatial memory test scores between the test group and the contrast group, and $\mathrm{P}>0.05$. After training, the correct rate of memory in the test elderly patients with $\mathrm{MCI}$ is higher than that of the contrast MCI elderly, and $\mathrm{P}=0.03<0.05$, which indicates that sensory integration training promotes the short-term memory ability of old people with MCI. The most prominent data appeared in the "Wrong directions" item. The project judges whether the MCI old people understand the four orientations centered on themselves by using the wrong number of questions. The results show that the success rate of the MCI elderly in the test group after training with the up and down direction is as high as $100 \%$. However, compared with the contrast group, there is no significant difference in the "right and left" direction error rate, and $\mathrm{P}>0.05$. That indicates sensory integration training has a certain role in promoting the ability of the MCI elderly to recognize the "up and down" direction but the effect is not obvious, and has basically no effect on the recognition of "left and right" direction. By observing the $\mathrm{P}$ data, there is no significant difference in changes of data between the test group and the contrast group before and after training for MCI elderly. From this, two results can be obtained, the subject's own spatial memory ability is better or there is weak part of the training content design. According to the estimation of the characteristics of elderly people in MCI, they generally do not have strong spatial perception and memory ability. Therefore, the sensory integration training program needs to be further discussed and adjusted for this part.

The fifth experiment is the visual tracking test, as shown in Table 5, which is a comparative analysis of the visual tracking test results between the test group and the contrast group.
Table.5 Comparison and Analysis of Visual Tracking Test Results between Test Group and Control Group

\begin{tabular}{|c|c|c|c|c|}
\hline \multirow{2}{*}{$\begin{array}{c}\text { Test } \\
\text { items }\end{array}$} & $\begin{array}{c}\text { Training } \\
\text { phase } \\
\text { (before } \\
\text { or after) }\end{array}$ & $\begin{array}{c}\text { test } \\
\text { group } \\
(\mathrm{N}=7)\end{array}$ & $\begin{array}{c}\text { contrast } \\
\text { group } \\
(\mathrm{N}=7)\end{array}$ & $\mathrm{P}$ \\
\hline \multirow{4}{*}{$\begin{array}{c}\text { Correct } \\
\text { questions } \\
\mathrm{P}\end{array}$} & before & $\begin{array}{r}2.85 \pm \\
1.86\end{array}$ & $\begin{array}{r}2.42 \pm \\
2.14\end{array}$ & 0.62 \\
\cline { 2 - 5 } & after & $\begin{array}{c}4.71 \pm \\
0.75\end{array}$ & $\begin{array}{c}2.57 \pm \\
1.98\end{array}$ & 0.02 \\
\cline { 2 - 5 } & & 0.02 & 0.84 & \\
\hline \multirow{4}{*}{$\begin{array}{c}\text { The time } \\
\text { spent } \\
\mathrm{P}\end{array}$} & before & $\begin{array}{c}92.85 \pm \\
24.20\end{array}$ & $\begin{array}{c}91.14 \pm \\
26.02\end{array}$ & 0.84 \\
\cline { 2 - 5 } & after & $\begin{array}{c}38.57 \pm \\
10.89\end{array}$ & $\begin{array}{c}84.42 \pm \\
19.06\end{array}$ & 0.000 \\
\cline { 2 - 5 } & & 0.000 & 0.42 & \\
\hline \multirow{3}{*}{$\begin{array}{c}\text { Test } \\
\text { score } \\
\mathrm{P}\end{array}$} & before & $\begin{array}{c}54.14 \pm \\
37.28\end{array}$ & $\begin{array}{c}48.57 \pm \\
42.98\end{array}$ & 0.63 \\
\cline { 2 - 5 } & after & $\begin{array}{c}94.28 \pm \\
15.11\end{array}$ & $\begin{array}{c}51.42 \pm \\
39.76\end{array}$ & 0.02 \\
\cline { 2 - 5 } & & 0.02 & 0.83 & \\
\hline
\end{tabular}

Table 5 shows that there was no significant difference in visual tracking test scores between the test group and the contrast group before training, and $\mathrm{P}>0.05$. After the training, the test scores of the MCI elderly in the test group are significantly higher than those in the contrast group, and $\mathrm{P}<0.05$. The visual tracking test is a test method that reflects the effective concentration of the elderly in the MCI. The "Correct questions" indicates that the elderly MCI tested focus on the results of the concentration. The more correct questions, the better the ability of the MCI elderly people maintain their attention. The data in the table shows that after training, the accuracy of the test group is significantly higher than that of the contrast group, and the accuracy of the five subjects is basically correct. This result shows that sensory integration training has a significant effect on the improvement of the ability of the concentration with the MCI elderly. "The time spent" indicates that the MCI elderly spends the time to concentrate on completing all the topics, and is also one of the indicators of the degree of concentration ability. After the training, the completion time of the MCI elderly in the test group (mean of 38 seconds) is significantly faster than the contrast group (mean of 84 seconds). The difference is particularly significant, which indicates that sensory integration training can improve the concentration efficiency that the MCI elderly people completed. The last "Test score" reflects the comprehensive scores of the elderly MCI's concentration ability (correction rate and efficiency, similarly, $\mathrm{P}=0.02<0.05$, so the MCI elderly person's performance is significantly improved.

\section{CONCLUSION}

Old mild cognitive impairment is between normal aging and Alzheimer's disease. At present, there is no specific drug for this disease in China. In this paper, the effect of 
sensory comprehensive training on mental mobility of MCI elderly people is studied. According to this study, some conclusions can be drawn as follows. Cognitive ability mainly includes the ability of language development and spatiotemporal orientation. Sensory integration training is conducted in the form of games. It often requires mutual cooperation and mutual coordination among the participants to work together, which promotes more communication and exchanges among the elderly in MCI. This kind of communication is beneficial to strengthen the ability of language expression in the MCI elderly and to weaken the degeneracy of MCI elderly language expression ability. Space-time orientation includes outbound, public transportation, time concepts, and comprehensive orientation capabilities. Sensory integration training uses balance bicycles to enrich the vestibular sense of the elderly MCI so that they can achieve to maintain the cognitive ability of time and space by observing and perceiving the action image, strengthening each movement form, exercise sequence, spatial feeling, time sense, and interaction between body parts. Of course, there are some areas worth deepening in this study. For example, in the future development, how to use sensory comprehensive training strengthen the cognitive abilities of the MCI elderly and at the same time improve their social self-control ability.

\section{Acknowledgment}

Shandong Province medical and health science and technology development project name: Influence of sensory integration training on mental mobility of elderly people with MCI.

Project number:2016WS0251

\section{Introduction to the author}

Zhang Hongmei, female, December 1974, lecturer, graduate student, nurse in charge, now engaged in nursing teaching, research direction: geriatric nursing, postcode: 266555 .

\section{References}

1. Myer G D, Faigenbaum A D, Chu D A, et al. Integrative training for children and adolescents: techniques and practices for reducing sports-related injuries and enhancing athletic performance $[\mathrm{J}]$. The Physician and sportsmedicine, 2011, 39(1): 74-84.

2. Boswell J F, Nelson D L, Nordberg S S, et al. Competency in integrative psychotherapy: Perspectives on training and supervision[J]. Psychotherapy: Theory, Research, Practice, Training, 2010, 47(1): 3 .

3. Hernández P, Engstrom D, Gangsei D. Exploring the impact of trauma on therapists: Vicarious resilience and related concepts in training $[\mathrm{J}]$. Journal of Systemic Therapies, 2010, 29(1): 67.

4. Bell B S, Kozlowski S W J. Toward a theory of learner-centered training design: An integrative framework of active learning $[\mathrm{J}]$. Learning, training, and development in organizations, 2010: 263-300.

5. Lowndes L, Hanley T. The challenge of becoming an integrative counsellor: The trainee's perspective[J]. Counselling and Psychotherapy Research, 2010, 10(3): 163-172.

6. Petersen R C. Mild cognitive impairment[J]. New England Journal of Medicine, 2011, 364(23): 2227-2234.

7. Petersen R C, Roberts R O, Knopman D S, et al. Mild cognitive impairment[J]. Arch Neurol, 2009, 66(12): 1447-1455.

8. Albert M S, DeKosky S T, Dickson D, et al. The diagnosis of mild cognitive impairment due to Alzheimer's disease: Recommendations from the National Institute on Aging-Alzheimer's Association workgroups on diagnostic guidelines for Alzheimer's disease[J]. Alzheimer's \& dementia: the journal of the Alzheimer's Association, 2011, 7(3): 270-279.

9. Frank A R, Petersen R C. Mild cognitive impairment[J]. Handbook of clinical neurology, 2008, 89: 217-221.

10. Torpy J M, Lynm C, Glass R M. Mild cognitive impairment[J]. Jama, 2009, 302(4): 452-452. 